\title{
An Evolutionary Genetic Perspective of Eating Disorders
}

\author{
Alexandra J. Mayhew $^{a}$ Marie Pigeyre ${ }^{a, b}$ Jennifer Couturier ${ }^{c}$ David Meyre ${ }^{a, d}$ \\ a Department of Health Research Methods, Evidence, and Impact, McMaster University, Hamilton, ON, Canada; \\ ${ }^{b}$ Department of Nutrition, Lille University, Lille, France; Departments of ${ }^{\mathrm{C} P s y c h i a t r y}$ and Behavioral Neurosciences, \\ and ${ }^{\mathrm{d} P a t h o l o g y}$ and Molecular Medicine, McMaster University, Hamilton, ON, Canada
}

\section{Keywords \\ Eating disorders - Binge eating disorder - Anorexia nervosa $\cdot$ Bulimia nervosa $\cdot$ Heritability $\cdot$ Molecular genetics · Evolution}

\begin{abstract}
Eating disorders (ED) including anorexia nervosa (AN), bulimia nervosa (BN), and binge eating disorder (BED) affect up to $5 \%$ of the population in Western countries. Risk factors for developing an ED include personality traits, family environment, gender, age, ethnicity, and culture. Despite being moderately to highly heritable with estimates ranging from 28 to $83 \%$, no genetic risk factors have been conclusively identified. Our objective was to explore evolutionary theories of EDs to provide a new perspective on research into novel biological mechanisms and genetic causes of EDs. We developed a framework that explains the possible interactions between genetic risk and cultural influences in the development of ED. The framework includes three genetic predisposition categories (people with mainly AN restrictive gene variants, people with mainly BED variants, and people with gene variants predisposing to both diseases) and a binary variable of either the presence or absence of pressure to be thin. We propose novel theories to explain the overlap-
\end{abstract}

ping characteristics of the subtypes of AN (binge/purge and restrictive), $\mathrm{BN}$, and $\mathrm{BED}$. For instance, mutations/structural gene variants in the same gene causing opposite effects or mutations in nearby genes resulting in partial disequilibrium for the genes causing AN (restrictive) and BED may explain the overlap of phenotypes seen in AN (binge/purge).

(c) 2017 S. Karger AG, Basel

\section{Introduction}

The Diagnostic and Statistical Manual of Mental Disorders, version 5 (DSM-5) describes three eating disorders (EDs): anorexia nervosa (AN), bulimia nervosa $(\mathrm{BN})$, and binge eating disorder (BED). EDs affect around $5 \%$ of the population in Western countries, and are more prevalent in females than males [1]. EDs develop from a complex interaction of psychological risk factors, sociocultural influences, and biological and genetic predispositions $[2,3]$. Although heritability estimates range from 28 to $78 \%$ for AN, 30 to $83 \%$ for BN [4], and 41 to $57 \%$ for BED [5], there is limited evidence of robust associations between EDs and candidate genes or associations detected through genome-wide association studies (GWAS) or whole-exome/genome sequencing [6]. The high herita-

\section{KARGER}

(c) 2017 S. Karger AG, Basel

E-Mail karger@karger.com

www.karger.com/nen
David Meyre

Department of Health Research Methods, Evidence, and Impact

McMaster University, 1280 Main St.

Hamilton, ON L8S 4K1 (Canada)

E-Mail meyred@mcmaster.ca 
bility and ethnic-dependent prevalence of EDs suggests a possible influence of natural selection; however, theories examining EDs from an evolutionary perspective are limited. The purpose of this article is to investigate the epidemiological, genetic, and biological evidence about ED and to use this information to inform new evolutionary genetic theories of ED. These theories can be used to stimulate research into novel biological mechanisms and genetic causes of ED. A qualitative review of the literature related to the epidemiology (diagnostic criteria, prevalence, time trends, risk factors), neurotransmitters, and genetic determinants (heritability, linkage studies, candidate gene studies, GWAS, and next-generation sequencing) of EDs was conducted (November 2016, no restriction on publication date of articles) using PubMed, Google Scholar, and the MEDLINE databases.

\section{Epidemiology of EDs}

\section{Diagnostic Criteria of EDs}

People with AN are significantly underweight, have an intense fear of gaining weight or becoming fat, a disturbance in body image, a heavy emphasis on body shape for self-evaluation, and/or denial of the seriousness of their current weight loss [7]. There are two subtypes of AN: the restricting type (ANR), involving food restriction without binging or purging, and the binge-eating/purging type (ANBP), involving overeating and/or purging. Similar to AN, people with $\mathrm{BN}$ place a strong emphasis on body shape for self-evaluation, but are not underweight. $\mathrm{BN}$ also involves recurrent episodes of binge eating during which large quantities of food are consumed during a discrete period of time. During these episodes, people feel a lack of control and are unable to stop eating. After binges, inappropriate compensatory behaviors including selfinduced vomiting, laxative misuse, diuretics, enemas, excessive exercise, or abuse of medications are used to prevent weight gain. This behavior must occur a minimum of once a week for 3 months to be diagnosed as BN. Individuals with BED do not engage in compensatory behavior and are at high risk of being obese [7]. Over self-evaluation of shape and weight is not a diagnostic criterion for BED, but can be present in individuals with this disorder [8]. It is noteworthy that some overlapping EDs are described in the DSM-5 under the "Other Specified Feeding or Eating Disorders" but will not be covered in this review [7].

\section{Prevalence of EDs}

The lifetime prevalence of AN is $0.3-3.0 \%$ for females and $0.24-0.30 \%$ for males with a peak incidence between 10 and 19 years of age [1,9-21]. BN is similarly more prevalent in females, with $0.88-4.6 \%$ of females suffering from the disease compared to $0.10-1.5 \%$ of males $[1,10$, $11,13,15,16,22,23]$. There is greater variability in the estimates of peak incidence of $\mathrm{BN}$, which in part could be because of the use of different age cut-offs used in studies as well as the relatively recent changes in diagnostic criteria. The peak incidence is estimated to be as low as 1020 years of age, or as high as 25-29 years $[11,12,14,16$, $22,24]$. The lifetime prevalence of BED is higher in females $(2.5-3.5 \%)$ compared to males (1.5-2.0\%) [1, 2427]. Three studies have found that the incidence of BED is relatively equally distributed across the lifespan $[24,28$, 29], while another indicated that the average age at onset of BED ranges from 18.3 to 25.4 years [10].

Ethnicity and culture may alter the prevalence of ED. The prevalence of $\mathrm{AN}$ in non-Western countries is estimated to be $0.002-0.9 \%$ compared to $0.3-3.0 \%$ for females and $0.24-0.30 \%$ in males in Western countries [30]. A study in Curacao found the incidence of AN is 1.82 cases per 100,000 persons per year without any cases in Black females [31], and in the United States, $0 \%$ of Black females were diagnosed with AN in contrast to $1.5 \%$ of White females [32]. Also in the United States, the lifetime prevalence of AN in the adult population was $0.15 \%$ for African-Americans and $0 \%$ for Caribbean Blacks [33]. BN is also less prevalent in non-Western countries compared to Western countries. A meta-analysis found that there are no studies in non-Western countries reporting the presence of $\mathrm{BN}$ without exposure to Western ideals [34] and in the United States, 2.3\% of White females versus $0.4 \%$ of Black females received a diagnosis of $\mathrm{BN}$ [32]. In contrast, $\mathrm{BED}$ appears to be more prevalent in African-Americans and Caribbean Blacks compared to Whites. Some studies conducted in Latino populations suggest that the prevalence for Latinos is also higher than for Whites $[17,28,33,35,36]$.

It is unclear if the prevalence of EDs has changed over time. Most studies indicate that the prevalence of $\mathrm{AN}$, $\mathrm{BN}$, and BED has increased [12, 34, 37]; however, there are studies that have observed declines in prevalence [12, 38]. Changes in the prevalence may not reflect true changes in the number of people with EDs but may instead represent changes in diagnostic criteria, shifting attitudes about mental health disorders, the challenge of identifying patients who often try to keep their disease hidden, differing methodologies [34], and small sample sizes from groups that are not generalizable. 


\section{Risk Factors of EDs}

\section{Personality Traits}

Personality characteristics are associated with EDs, including perfectionism, obsessive compulsive personality, neuroticism, negative emotionality, harm avoidance, low self-directedness, low cooperativeness, and features of avoidant personality disorder $[39,40]$. Low novelty seeking, low emotional responsiveness, decreased pleasure, decreased seeking of pleasure, and reduced social spontaneity are common characteristics in individuals with the restrictive type of $\mathrm{AN}$, while those with $\mathrm{BN}$ tend to be impulsive, seek out new experiences, and have characteristics of borderline personality disorder $[39,40]$. BED is associated with perfectionism and sensation seeking, and both $\mathrm{AN}$ and $\mathrm{BN}$ are associated with obsessive compulsive personality disorder [39]. Though causality has not been established, psychiatric comorbidities are frequent in all EDs with an estimated prevalence between 31.0 and $88.9 \%[1,19,21,41]$. Depression and anxiety disorders are most prevalent $[16,21,41-43]$; however, bipolar affective disorder, obsessive compulsive disorder, and substance use are also common [21].

\section{Environmental Exposures}

Individuals diagnosed with EDs are more likely to have experienced abuse or trauma than the general population. Specifically, sexual abuse has been reported in 20$50 \%$ of individuals with AN and BN. Women with EDs who have suffered from sexual abuse also demonstrate higher rates of comorbid psychiatric conditions [7]. Inadequate coping mechanisms are common in those with disordered eating and may explain an individual's adoption of maladaptive eating patterns in response to trauma [44]. Studies have also noted a higher prevalence of EDs among athletes, models, dancers, and performers, activities which emphasize dietary restraint and idealize a thin physique [2]. Family dynamics that involve overprotective, intrusive, controlling, or emotionally unresponsive parents, as well as enmeshment of parents and children and poor conflict resolution have been associated with EDs, though evidence is limited [45-48]. Having a preoccupation with weight in the form of family dieting or receiving criticism about weight, eating, or body shape, is also associated with the risk of EDs [49].

\section{Neurobiological Regulation}

Several neural systems have been implicated in the etiology of EDs, including those associated with cognitive self-regulatory control, motivation and reward process- ing, as well as hunger regulation $[40,50,51]$. Disturbances of brain serotonin activity have been described in acutely ill as well as long-term recovered patients with both AN and BN [40]. It is hypothesized that a disturbance of serotonin activity may create vulnerability for the development of EDs. Alterations in central nervous system serotonin function may contribute to other psychological symptoms associated with EDs, such as the high prevalence of depressive disorders, the impulsiveaggressive behavior observed in patients with $\mathrm{BN}$, and the obsessive-compulsive symptomatology observed in AN. Serotonin activity may also contribute to symptoms such as anxiety, perfectionism, obsessions with symmetry and exactness, and harm avoidance, which, when coupled with psychosocial influences, make people vulnerable to developing AN [52]. Dysfunction of the neural network involved in reward, punishment, and motivational processes is also described in ED patients [40,53]. Several studies have shown that dopamine system disturbance contributes to the development and maintenance of AN and other EDs $[54,55]$.

\section{Genetic Determinants of EDs}

Different strategies have been used to determine the genetic and epigenetic architecture of EDs including heritability studies, linkage studies, candidate gene approaches, GWAS, next-generation sequencing, candidate gene and whole-genome methylation studies. Linkage studies use related individuals to identify genomic regions containing genes that predispose individuals to a disease [56]. Candidate gene studies investigate genes that have been selected based on their physiological, biochemical, and functional aspects [57]. GWAS are hypothesis-free study attempts to identify common genetic variants that contribute to disease risk using markers covering the entire genome [58]. Next-generation sequencing approaches target rare genetic variants and short deletion/duplication that contribute to ED etiology. Methylation arrays enable the quantitative interrogation of methylation sites across the genome at single-nucleotide resolution [59].

\section{Heritability of EDs}

EDs are moderately to highly heritable. Heritability estimates from twin studies range from 28 to $74 \%$ for AN, 54 to $83 \%$ for BN, and 41 to $57 \%$ for BED [5]. Most of the individual studies contributing to these estimates have wide confidence intervals because of the low statistical 
power caused by relatively small sample sizes due to the low prevalence of EDs [5]. The range of estimates also reflects that heritability estimates can include just additive genetic effects or all genetic effects including gene $\times$ gene interactions and dominant effects $[60,61]$. One of the limitations of the heritability estimates is that the studies are predominantly conducted in Europeans. However, a study conducted in both European American and African-American female twins suggests that the contribution of additive genes to $\mathrm{BN}$ and $\mathrm{BED}$ are similar $[62,63]$.

\section{Linkage Studies}

Few linkage studies have been performed for ED traits, and none of them used a logarithm of odds (LOD) score of 3.6 as the threshold for significant linkage [64]. In a genome-wide linkage analysis of 192 families with at least one affected relative pair with AN and related EDs, only a modest evidence of linkage with $\mathrm{AN}$ was reported on chromosome 4 (LOD of 1.80). However, the analysis of the subset of patients with the restrictive subtype of AN led to the identification of a linkage peak close to significance on chromosome 1p36-34 (LOD of 3.03 and of 3.45 after genotyping additional microsatellite markers) [65]. Devlin et al. [66] developed an original methodology based on the linkage study of AN incorporating behavioral covariates. Applying this method to 196 multiplex families, they identified a linkage close to significance (LOD of 3.46) for AN, obsessionality and drive-for-thinness. The analysis of 308 families with $\mathrm{BN}$ led to the identification of a suggestive peak of linkage on chromosome 10p13-12 (LOD of 2.92). When the analysis was restricted to 133 families with $\mathrm{BN}$ and self-induced vomiting, the linkage value increased at the same location (LOD of 3.39) [67]. Interestingly, significant linkage for obesity has been identified in the same chromosomal region [6870]. Though noteworthy, these findings are not statistically significant and are from insufficiently powered studies, increasing the risk of false positive results [71]. Furthermore, these linkage experiments have not been confirmed by positional cloning, and no strong predisposing genes have emerged to date [4].

\section{Candidate Gene Studies}

Hundreds of candidate gene studies of common variants have been published, but have provided few definitive conclusions [72]. Regardless of the type of ED, most candidate gene studies have focused on genes related to homeostatic control and reward systems due to the hypothesized shared roles of these pathways to all ED. The main pathways explored in candidate gene studies of ED include: (a) homeostatic pathways (leptin melanocortin pathway genes, i.e. LEP, LEPR, POMC, AGRP, MC4R, $B D N F$ genes, as well as GHRL, FTO genes) and (b) reward-related pathways including central neurotransmission of serotonin (i.e., HTR1D, HTR2A, HTR2C, SLC6A4 genes), dopamine (i.e., DRD2, DRD4, ANKK1 genes), noradrenaline (COMT gene), opioid (OPRD1, OPRM genes) and the cannabinoid endogenous system (CNR1 gene). These pathways are relevant to candidate gene studies because healthy eating behavior is achieved through the balance of homeostatic controls and reward processes. Dysregulation of these systems is observed in EDs, but it is currently unknown if alterations to these pathways are a cause or an effect [73]. Overall, these studies do not show a conclusive association between a common single nucleotide polymorphism (SNP) and EDs [74]. The contribution of common variants associated with body mass index (BMI) variation to EDs has been recently tested in 3 studies, but the results are conflicting [75-77]. However, a recent atlas of genetic correlations across human diseases supports a shared molecular basis for AN and obesity [78].

\section{Genome-Wide Association Studies}

Unsurprisingly, several modestly powered GWAS studies for ED-related traits reported negative findings after correcting for multiple testing $[79,80]$. A recent negative two-stage GWAS meta-analysis for AN in 5,551 cases and 21,080 controls concluded that the accrual of large genotyped AN case-control samples should be an immediate priority for the field to identify AN-predisposing genes [81]. Although there were no genome-wide significant hits reported, 72 independent markers with the lowest $p$ values were selected for replication in an independent sample, and $76 \%$ of these loci produced results directionally consistent with the discovery sample [82]. Two AN loci have successfully been identified by GWAS. A study including 692 female AN cases and 2,570 controls found a significant association approaching genome wide significant $\left(p=2.04 \times 10^{-7}\right)$ between a variant in the Early B-Cell Factor 1 (EBF1) gene (rs929626). The inactivation of EBF1 in mice leads to a decrease in circulating leptin levels, in line with the observations of very low leptin levels made in human AN patients. In addition, another SNP (rs4704963) in EBF1 showed genome-wide significant interaction with psychosocial stress on obesity traits [83]. In a sample of 3,495 AN cases and 10,982 controls, rs4622308 near the v-erb-b2 avian erythroblastic leukemia viral oncogene homolog 3 (ERBB3) gene was significantly associated with AN [84]. Further replication studies, larger sam- 
ple sizes, and experiments on expression and function are required to gain a better understanding of the role of these genes in AN. Thus far, there have not been any GWAS conducted in BN or BED, though a large GWAS in 2,564 female twins investigating ED-related phenotypes did not find any significant associations $\left(p<10^{-8}\right)$ with $\mathrm{BN}$ spectrum, purging via substances, disordered eating behaviors, or AN spectrum [85].

\section{Next-Generation Sequencing}

A recent whole-exome/-genome sequencing study in 2 large multigenerational pedigrees affected by multiple EDs identified the estrogen-related receptor- $\alpha$ (ESRRA) and the histone deacetylase 4 (HDAC4) genes as promising candidates to further investigate in additional studies [86]. HDAC4 is expressed in the brain, including the cortical region implicated in EDs [87] and has a known role in synaptic plasticity [88]. These findings support that a decrease in ESRRA activity may impact the neuronal dysfunction in ED patients. Additionally, ESRRA has a wellestablished role in mitochondrial regulation of neuronal plasticity [89]. Finally, ESRRA induces the expression of both monoamine oxidase $\mathrm{A}$ and $\mathrm{B}$, suggesting a potential role in the metabolism of monoamine neurotransmitters such as serotonin and dopamine [90]. Moreover, given the female predominance of EDs, it is possible that estrogen signaling may mediate the risk of EDs by altering ESRRA-HDAC4 activity [91].

\section{Copy Number Variants}

Copy number variants (CNV) consist of small deletions or duplications in the genome. The only genomewide CNV study of EDs reported a 1.4-Mb deletion on 13 q12 in 2 AN cases [80]. A genome-wide search for copy-number variants associated with $\mathrm{BMI}$, found a $600-\mathrm{Kb}$ deletion on chromosome 16p11.2 associated with a highly penetrant form of obesity accompanied by hyperphagia and increased ad libitum food intake $[92,93]$. SH2B1, one of the genes deleted, encodes a protein involved in leptin signaling and is the best candidate to account for the hyperphagic obesity phenotype observed in deletion carriers [94]. Deletion carriers also exhibited subjective alteration of reward, eating in the absence of hunger and sensitivity to external cues [95], but do not present with BN or BED [96]. Conversely, a duplication at the same chromosome 16p11.2 locus has been associated with failure to thrive in children and underweight in adults, with a high frequency of selective and restrictive eating behaviors [97]. Unfortunately, all these findings have not yet been replicated.

\section{Epigenetics}

Epigenetic mechanisms provide a substrate for geneenvironment interactions. Starvation is a key clinical feature of patients with $\mathrm{AN}$, and a strong environmental exposure can be expected to trigger epigenetic alterations [98]. A main epigenetic mechanism is DNA methylation. Hypermethylation of the alpha-synuclein (SNCA) gene (linked to sensitivity to dietary folate) [99], the atrial natriuretic peptide (NPPA) gene, implicated in anxiety, depression, and stress responses [100], and the oxytocin receptor $(O X T)$ gene [101] have been associated with AN. Weight loss can also alter methylation and expression of the pro-opiomelanocortin (POMC) gene, implicated in hunger, satiety, and energy homeostasis [102]. AN and $\mathrm{BN}$ subjects showed increased methylation of dopamine system genes [103]. Taken together, these findings suggest that alterations in DNA methylation can lead to EDs by influencing a wide variety of systems implicated in behavioral/affective regulation, sensitivity to nutritional insufficiencies, and body-weight maintenance [99, 104, 105]. Genome-wide methylation profiles in women with AN-restrictive type, and women with AN-binge/purge type compared with normal-weight/normal-eater control women, showed higher and less variable global methylation patterns in AN than controls [59]. Hypermethylation concerned 11 genes (PRDM16, HDAC4, TNXB, FTSJD2, PXDNL, DLGAP2, FAM83A, NR1H3, DDX10, ARHGAP1, PIWIL1) involved in histone acetylation, RNA modification, cholesterol storage and lipid transport, and dopamine and glutamate signaling [59]. Further confirmation of these initial findings is needed at this stage. For instance, the hypermethylation of TNXB has been recently confirmed by high-throughput DNA methylation analysis in AN [106]. Developmental experiences and early adversity can also impact methylation levels of neuropsychiatric genes and, in turn, create variations in phenotypes related to stress reactivity and mood regulation [107]. DNA hypermethylation of the glucocorticoid receptor gene (NR3C1) has been observed on individuals with a history of childhood abuse, compared to individuals who did not report experiences of maltreatment [107].

\section{Gender Influences on Genetic and Environmental Risk} Factors of ED

Genetic and environmental influences on EDs appear to be moderated by sex and developmental stage. The female to male ratio for EDs is between 4:1 and 10:1 [7], and there is a significant increase in EDs in females during puberty. When investigating heritability in males and females separately, heritability appears higher in females 
(51-61\%) than in males $(0-40 \%)$ for intentional weight loss, body dissatisfaction, drive for thinness [108-110], and weight concerns [111]. A moderate overlap is also suggested in the genetic factors influencing ED symptoms including body dissatisfaction, drive for thinness [112], and behaviors such as binge eating $[42,113]$ between genders. This moderate overlap may be explained by sexual dimorphism and different levels of sex hormones. In Mendelian disorders, an exceptionally high female to male ratio suggests a higher rate of mutation of disease-causing genes located on the $\mathrm{X}$ chromosome in sperm cells or a high rate of $\mathrm{X}$ inactivation of one gene copy or a dominant inheritance mode [114]. It is also possible that some $\mathrm{Y}$ chromosome genes are protective against EDs. Together, these may account for the increased genetic risk of EDs in females versus males. The genetic and biological differences between males and females may also interact with environmental factors to alter the risk for developing EDs. Adolescence is also a key developmental period for EDs. Longitudinal twin studies have found that the genetic influences on EDs increase from early to late adolescence [115-117]. One possible explanation is that hormonal changes occur at puberty including an increase in estradiol. Estradiol regulates gene transcription within the central nervous system [118] and during puberty may activate genetic factors for EDs. This theory is supported by recent ED-related genetic variants found to be involved in estrogen metabolism [86]. Estrogens are also involved in the regulation of appetite during the ovarian cycle and between puberty and reproductive senescence in women [119]. Other sex hormones can influence orosensory capacity, hedonics, and homeostasis of food intake via a modulation of gastric mechanoreception, and hormones (i.e., ghrelin, CCK, glucagon-like peptide-1, insulin, amylin, and leptin) as well as central neurochemical signaling (i.e., serotonin, dopamine, and leptin melanocortin pathway) [119].

\section{Limitations of Genetic and Epigenetic Approaches}

Across all methodologies, a common limitation to identification of genetic variants for EDs is sample size. Only 2 studies to date have identified SNPs significantly associated with AN $[83,84]$. To gain the statistical power necessary for further genome-wide significant results, research efforts should focus on the recruitment of large case-control cohorts. While boosting sample size, future GWAS efforts should also include BN, BED, as well as analysis of large male cohorts alongside females in order to make meaningful discoveries about the genetic risk factors for EDs in men. Differentiating between ANBP and ANR subtypes may also help detect associations if the SNPs contributing to these AN subtypes are unique. The more promising results that emerged from recent epigenetic studies deserve further confirmation in additional samples.

\section{Evolutionary Theories of EDs}

A complex and dynamic interplay between personality, life experiences, shared and unique environmental factors, epigenetic marks, and genetic predisposition (Fig. 1) is involved in the development of EDs. Examining the evolutionary theories of EDs can help future gene identification efforts by focusing on novel candidate genes as well as guiding the development of biological evidence to support the findings of GWAS. With the increasing use of GWAS approaches, evolutionary theories of EDs can also help determine new phenotypes to investigate. The limited success of genetic studies so far may also result from a focus on symptoms of the disorders, rather than the causes of them. For AN and BN, abnormal neurotransmitter and hormone levels have been widely observed, but genetic association studies have been inconsistent. If the altered neurotransmitter and hormone levels are a consequence of a physiological adaptation to low food consumption rather than one of the causes of the low food consumption as we propose, then we would not expect genes involved with the production and reception of those neurotransmitters and hormones to be altered in EDs. There is also the possibility that hormones relevant to EDs are yet to be discovered. Investigating metabolites, transcription factors, and protein profiles in people with EDs and comparing these to levels after recovery of the disease or between episodes as well as with controls may help to identify novel biomarkers and pathways in the etiology of EDs. Using personal characteristics and environmental factors which have been identified as risk factors for EDs, we investigate previously identified evolutionary theories of EDs as well as discuss novel hypotheses.

\section{Previously Identified Theories of EDs}

Previous evolutionary theories of EDs include the suppression of reproduction theory [120], the sexual competition theory [121], the adapted to flee famine hypothesis [122], the thrifty gene hypothesis [123], and dual intervention point model [124]. Briefly, the suppression of reproduction theory states that $\mathrm{AN}$ was a method through which females could suppress reproduction when offspring survival was threatened. Females who were able to 


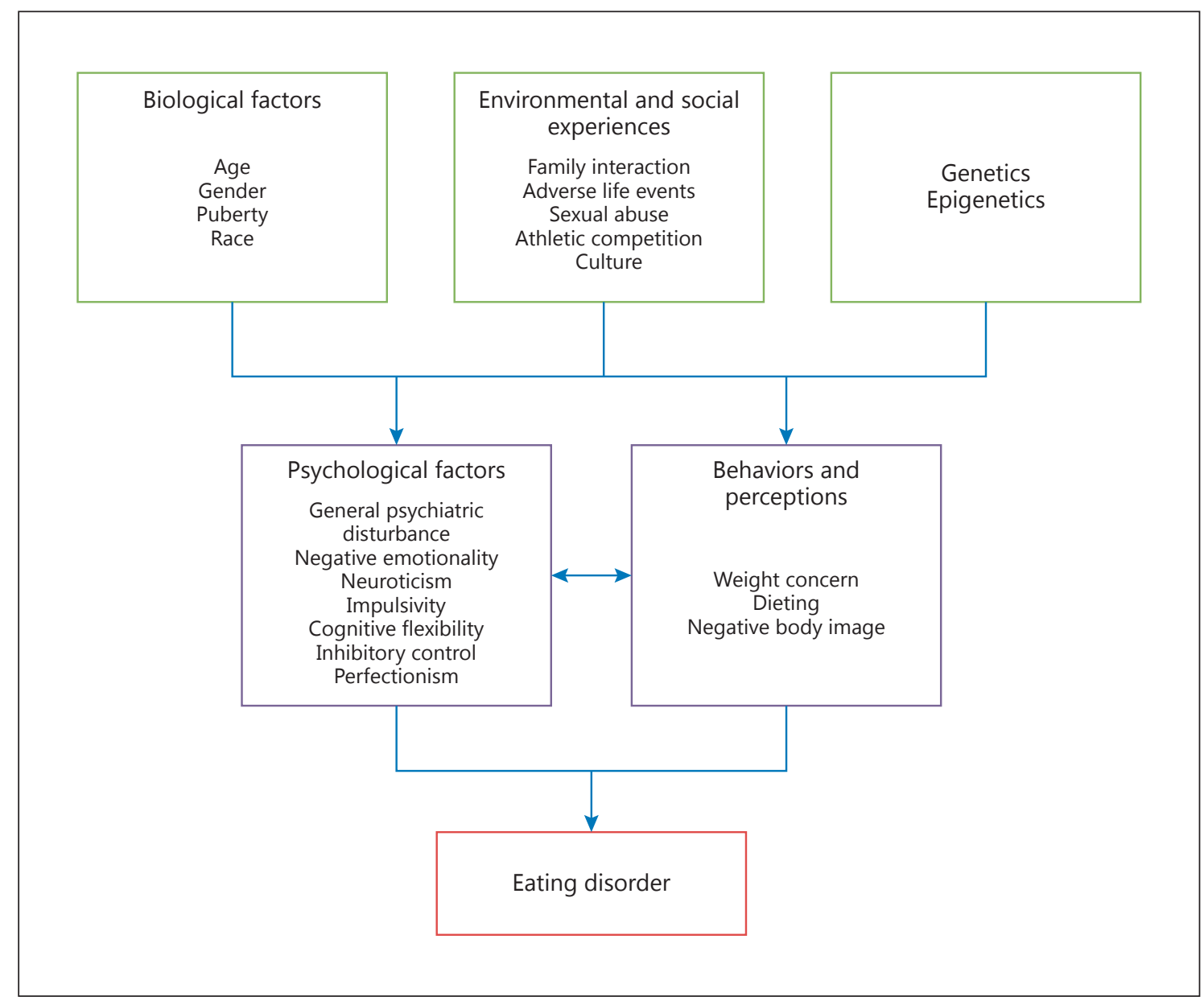

Fig. 1. The relationship between biological factors, environmental and social experience, genetic influences, psychological factors, and behaviors and perceptions in the development of eating disorders.

suppress reproduction until more favorable times are hypothesized to have higher overall reproductive success, therefore passing on the genes for AN characteristics [120]. The sexual competition theory suggests that AN was a method through which females could attract potential high-quality partners by maintaining a nubile shape and consequently increase their reproductive success [121]. The adapted to flee famine hypothesis explains a possible adaptive advantage to what are now known as symptoms of AN. It proposes that food restricting behavior, hyperactivity, and denial of seriousness of weight loss previously enabled migration during periods of local food insecurity allowing individuals to reach more food-secure areas. Individuals who survived the journey would be able to later reproduce explaining why the genes may have been passed on [122]. The previous theories provide potential explanations for $\mathrm{AN}$ but not for $\mathrm{BN}$ or $\mathrm{BED}$ symptoms. The leading theory for these EDs is the thrifty genotype hypothesis stating that extra fat stores were protective because they played a role in helping to avoid malnutrition, regulate reproduction, and allow for survival during variations in the energy supply [123]. An elaboration on the set point theory called the dual intervention point model may also explain excessive food consumption. This theory states that the body has upper and lower limits for weight, which when exceeded triggers physiological adaptations. The lower limit is set at the minimal weight necessary to avoid starvation while the upper weight previously was set to limit predation. As humans have evolved and predatory pressures have been reduced, it is theorized that the genes coding for a higher upper limit have become more common, and fewer people experience the physiological adaptations such as reducing caloric intake, that prevent weight gain [124]. These exist- 
ing theories are not widely accepted and though they provide interesting perspectives on the potential historical development of EDs, their applicability is limited especially considering that most people with $\mathrm{BN}$ are not overweight [125].

\section{Novel Theories of EDs}

The evolutionary theories of EDs clearly distinguish between AN and the other two EDs, BN and BED. However, the disorders have a significant amount of overlap. The diagnostic criteria for ANR includes weighing less than one should and consuming a limited amount of calories per day, while ANBP replaces the limited calories criteria with cycles of binging and purging [7]. ANBP is very similar to $\mathrm{BN}$, except that individuals with $\mathrm{BN}$ are not underweight. There is a significant amount of crossover between those with ANR, ANBP, and BN. In 7 years of follow-up, $49 \%$ of women initially diagnosed with AN crossed over between AN subtypes, 34\% crossed over from $\mathrm{AN}$ to $\mathrm{BN}$, and $18 \%$ of women initially diagnosed with $\mathrm{BN}$ crossed over to AN [20]. Below, we propose theories as to why the traits seen in BN, ANR, and ANBP overlap from a genetic perspective.

\section{Binge Eating as Protection against ED}

The denial of nutrients to the body seen in ANR could switch on a pathway encouraging the consumption of calories, explaining the binging behavior seen in people with the binge/purge subtype of AN. This fits with the adapted to flee famine hypothesis as people should resume eating when food is available again. The cross-over of patients from the subcategories of AN supports this theory when considering that more people cross over from the restrictive subtype to the binge/purge subtype than the contrary [20]. Approximately $25-30 \%$ of people receiving treatment for $\mathrm{BN}$ were previously diagnosed with $\mathrm{AN}$, while only $5 \%$ of people initially diagnosed with BN were later diagnosed with either subtype of AN [126]. The restrictive behavior seen in ANR may be difficult to maintain and consequently cross over to ANBP when the drive to eat becomes overwhelming. The cross-over of individuals from ANBP to BN shows that the binging behavior may slowly lead to weight gain, as the only diagnostic difference between $\mathrm{ANBP}$ and $\mathrm{BN}$ is that people with $\mathrm{AN}$ weigh significantly less than ideal [7]. However, this theory ignores that binge eating is seen outside of the context of $\mathrm{AN}$ in both BN and BED and that some people with ANR do not cross over to ANBP during the duration of their disease.

Genes, Evolution, and Eating Disorders
Accumulation of Independent Genes Leading to

Binge Eating and ED

Accounting for the limitations of the previous theory explaining the coexistence of binge/purging behavior with $\mathrm{AN}$, we hypothesize that independent genes may lead to the binge/purging behavior seen in $\mathrm{BN}$ and the extreme weight loss seen in AN. Through random segregation within populations, some people may cumulate both the genes predisposing to $\mathrm{AN}$ and the genes predisposing to $\mathrm{BN}$. This theory is unlikely because both $\mathrm{AN}$ and $\mathrm{BN}$ are relatively rare diseases. Using our estimated prevalence of $0.3-3.0 \%$ for $\mathrm{AN}$ and $0.88-4.6 \%$ for $\mathrm{BN}$ in females, the ANBP subtype should be between 0.0026 and $0.138 \%$, while the actual prevalence of ANBP is somewhere between 0.15 and $1.5 \%$ of women based on half of the people with AN having the binge/purge subtype [20]. Therefore, we can conclude that because the actual prevalence of ANBP is higher than would be expected from accumulation of independent genes leading to $\mathrm{BN}$ and $\mathrm{AN}$, the genes associated with the individual diseases are either in linkage disequilibrium (i.e., nonrandom combination of alleles at different loci which could result from evolutionary selection, population ancestry history, and genetic linkage), or the same genes are causing the two different diseases.

Mutations/Structural Gene Variations with Opposite

Effects in the Same Gene Lead to ED or ED

Mutations or structural variants such as deletion/duplication, gain of function/loss of function, gain of expression/loss of expression in the same genes may lead to $\mathrm{AN}$ and binging behavior. Genetic correlation analyses, conducted from GWAS for BMI and AN, provided evidence for a shared polygenic etiology between these two traits, such as overall genetic determinants for higher BMI decreases risk of AN [78]. However, this study does not exclude that some of BMI-increasing variants can also be associated with higher risk of $\mathrm{AN}$, especially when stressed by environmental changes. This ties in with the evolutionary theories as both the genes allowing for the consumption of large amounts of food when available and the ability to be highly functioning with minimal caloric intake may have been historically positively selected for under different environmental conditions and people with both types of mutations may have been favored [122, $123,127-130]$. In the past, people possessing both genetic characteristics may not have suffered from any negative side effects allowing for the transmission of the genes on to future generations. It is reasonable to think that the mixed phenotypes (i.e., ANBP) are now only problematic in the obesogenic environment. Weight concerns are

Neuroendocrinology 2018;106:292-306 
Table 1. Framework for genetic and environmental predisposition to eating disorders

\begin{tabular}{llll}
\hline & $\begin{array}{l}\text { Genes predisposing to } \\
\text { anorexia nervosa } \\
\text { (restrictive subtype) }\end{array}$ & $\begin{array}{l}\text { Genes predisposing to } \\
\text { anorexia nervosa (restrictive } \\
\text { subtype) and genes } \\
\text { predisposing to binge eating }\end{array}$ & $\begin{array}{l}\text { Genes predisposing to } \\
\text { binge eating }\end{array}$ \\
\hline $\begin{array}{l}\text { Presence of pressure } \\
\text { to be thin }\end{array}$ & $\begin{array}{l}\text { Anorexia nervosa } \\
\text { (restrictive subtype) }\end{array}$ & $\begin{array}{l}\text { Anorexia nervosa (binge/ } \\
\text { purge subtype) }\end{array}$ & Bulimia nervosa \\
$\begin{array}{l}\text { Absence of pressure } \\
\text { to be thin }\end{array}$ & $\begin{array}{l}\text { No disease - unless } \\
\text { anorexia nervosa is } \\
\text { triggered by factors } \\
\text { other than weight loss }\end{array}$ & Binge eating disorder & Binge eating disorder \\
\hline
\end{tabular}

a relatively modern concept and dieting to lose weight could trigger the metabolic changes allowing for survival despite low caloric consumption. However, if the same genes are also causing binging behavior, individuals may purge in order to balance the conflicting biological drives to survive with minimal caloric consumption and to take advantage of the food available to them. The possibility of a single gene having both loss of function and gain of function mutations is supported by recent findings on $M C 4 R$ and the $16 p$ locus where loss of function mutations/deletions lead to hyperphagic obesity while gain of function mutations/duplications lead to leanness and selective/restrictive eating behaviors [93, 97, 131-133]. However, several studies have reported contradictory results on the association between binge eating behavior and loss of function variants in MC4R [134-136]; and gain of function variants in $M C 4 R$ are not more frequent in AN patients than in the general population [137]. Analyzing whole-genome SNP array and whole-exome sequencing data and searching for complex patterns of mirror CNVs or enrichment in loss of function and gain of function mutations in ANBP cases may identify promising candidate genes that may be further validated in ANR, $\mathrm{BN}$, or BED cases.

Mutations in Nearby Genes Result in Partial Linkage Disequilibrium of ED and Binge Eating Traits

Similar to the theory that the same genes may contain loss of function/gain of function mutations causing the cross-over of traits seen in EDs is the theory that the genes coding for the different characteristics of EDs are in genes located near each other and in partial linkage disequilibrium. The co-occurrence of two distinct phenotypes because of the linkage disequilibrium of mutations located in different genes has been suggested in few studies on EDs. Epistatic interactions have been found between the serotonin transporter and the norepinephrine transporter genes [138] as well as the monoamine oxidase A genes in AN [139], and between the dopaminergic genes (DRD2/DRD4 and CMOT/DAT1), influencing both eating- and personality-related psychopathology [140].

\section{A Framework for EDs Integrating Genetic Evolutionary Theories and Epidemiological Evidence}

We combined the evolutionary perspective of EDs with the possibility of the genetic overlap causing mixed phenotypes, and the epidemiological evidence of differences in prevalence of EDs in different ethnicities and cultures to create a framework suggesting under which conditions each ED will occur (Table 1).

\section{Genetic Component}

The genes predisposing individuals to ANR and to binge eating are likely to overlap because they are in partial linkage disequilibrium, either because mutations/ structural variants within the same gene have opposite functional effects or because the genes are located close to each other. Therefore, a greater number of people would have characteristics of both diseases than would be expected if the gene variants were independent. Thus, 3 genetic predisposition categories were created, people with mainly ANR gene variants, people with mainly binge eating gene variants, and people with gene variants predisposing to both diseases. There are other genetic factors that contribute to the risk of developing EDs not captured in the model such as epigenetics, gene by gene interactions, gene by environment interactions in addition to the pressure of being thin, and any potential genetic factors which contribute to the predisposition of being more sensitive to the pressure of being thin. 


\section{Pressure to Be Thin Component}

Body dissatisfaction is one of the most consistent and robust risk and maintenance factors for EDs [141]. The sociocultural model of EDs [2] asserts that exposure to the Western concept of the ideal body type, often via magazines, television, and the internet, promotes internalization of a thin body ideal. Body dissatisfaction ensues when individuals evaluate their own body size negatively because it is thought to vary from the ideal. Subsequently, elevated BMI and increased awareness of body size have been linked to the onset of dieting and body dissatisfaction, both of which being prominent risk factors for EDs $[2,141,142]$.

\section{Ethnicity and Culture}

Based on the epidemiological evidence, it appears that the racial/ethnic and cultural origins of an individual may be an important driver of the desire to be thin. However, because the terms ethnicity, race, and culture are often used interchangeably and because of the strong association between biological backgrounds versus cultural backgrounds in many people, it is impossible to untangle the genetic versus social contributions of race/ethnicity/ culture. Despite these challenges, it is well established that White women are more concerned about weight and have lower weight ideals in comparison to Black women [143145]. These concerns about weight may explain the higher prevalence of AN in Western countries as well as White individuals compared to African-Americans and Caribbean Blacks [31-33]. Interestingly, when preoccupation with weight is removed as a diagnostic criteria for $\mathrm{AN}$, there was an increase in prevalence of $\mathrm{AN}$ of $0.21 \%$ in the African-American population, though there was no increase in the Caribbean Black population [33]. Similarly, the prevalence of AN is very similar in Western and nonWestern countries when weight concerns were removed as a diagnostic criteria $[34,145]$.

$\mathrm{BN}$ is also less prevalent in non-Western countries compared to Western countries, and there are not any studies in non-Western countries reporting the presence of BN without exposure to Western ideals [34]. This suggests that the culturally derived concept of being thin may be an important driver of the disease. Supporting this theory, a study of the Latino-American population found that recent immigrants have the lowest rates of $\mathrm{BN}$ while those who have resided in the United States for $70 \%$ or more of their lives have the highest rates [28]. Similarly, a study of Fijian adolescent and adult females found that acculturation to Western ideals was associated with increased body shape concerns [146] and watching Westernized televi-

Genes, Evolution, and Eating Disorders sion shows was associated with disordered eating habits such as self-induced vomiting [147]. The fact that White women are more concerned about weight and have lower weight ideals in comparison to Black women [143-145] may explain why White women in the United States have a higher prevalence of BN than Black women [32]. These studies suggest that the culture may play an important role in the development of $\mathrm{BN}$ by causing an idealization of a thin body type which drives people to use inappropriate compensatory methods after binging episodes.

Though there is a modest quantity of evidence, studies in the United States have consistently shown that the prevalence of $\mathrm{BED}$ is higher in African-American and Caribbean Blacks compared to Whites [17, 28, 33, 35, 36]. The higher prevalence of BED in Blacks compared to Whites may be explained by the lack of weight preoccupation. Even within the BED population, White females are significantly more concerned about eating, dietary restraint, body shape, and weight compared to Black females, despite on average being less overweight [143]. Because a smaller proportion of African-Americans have weight concerns, the population may be less likely to engage in purging behavior compared to their White American counterparts. Therefore, they receive a diagnosis of $\mathrm{BED}$ rather than $\mathrm{BN}$. In line with these data, a study found that when weight preoccupation was removed as a criterion, the prevalence of $\mathrm{BN}$ in African-Americans and $\mathrm{Ca}$ ribbean Blacks increased [33].

\section{Biological Factors}

Biological factors such as age, gender, and puberty status may also contribute to the risk of feeling pressure to be thin. Across all 3 EDs, the prevalence is higher in females than in males. In females, puberty is a risk period for the development of $\mathrm{AN}$ and $\mathrm{BN}$ which is at least partially mediated by the effects of estrogen. Girls that reach puberty earlier than their peers or are more advanced developmentally are at the highest risk. The relationship between puberty status in males and EDs is less clear [148]. The peak incidence of AN is between 10 and 19 years, which coincidences with puberty. The peak incidence of $\mathrm{BN}$ is less clear, but has been estimated to be between 10 and 20 years by some studies and up to 25-29 years in others. There are too few studies to adequately assess the relationship between puberty status or age with BED.

\section{Personality, Environmental, and Neurobiological}

Factors

Environmental factors such as family interaction, adverse life events, sexual abuse, and athletic competition 
are all associated with EDs and have been shown to be associated with an increase in the desire to be thin. The relationship between personality characteristics and the desire to be thin have not been established. However, it is conceivable that traits such as perfectionism and obsessive personality characteristics may be important drivers of idealizing a thin body type. Neurobiological differences relating to cognitive self-regulatory control, motivation, reward processing, and hunger regulation between people may also drive the desire to be thin. For example, serotonin is thought to contribute to the development of anxiety and perfectionism. Certain personality phenotypes such as depression and anxiety are common to all ED [16, 21, 41-43], while other characteristics are more frequently found in specific EDs. For example, low novelty seeking and decreased pleasure are common in the restrictive subtype of AN, impulsivity and novelty seeking are common to $\mathrm{BN}$, and $\mathrm{BED}$ is associated with perfectionism $[39,40]$. These underlying phenotypes have genetic contributions. Different combinations of these phenotypes and underlying genetic predispositions may also contribute to overlapping characteristics between the ED types.

\section{Perspectives}

Even if great progress in genetics and epigenetics have unveiled the pathophysiological architecture of many complex human diseases, most of the genes predisposing to EDs still remain to be discovered. The genetic heterogeneity in different ethnic groups invites collaborations in order to initiate multiethnic international recruitment and come up with novel methodologies to exhaustively study genetic associations. Methodological developments such as hypothesis-driven GWAS and methylation studies relaxing Bonferroni, case-control case design studies, Bayesian approaches [149], and deep phenotype-based cohorts $[72,150]$ may boost the identification of novel ED-predisposing genes. Moreover, the real effect of genes and their interplay with environmental risk factors is not completely understood yet. Taking advantage of $\mathrm{G} \times \mathrm{E}$ interactions can lead to original experimental designs, such as genome-wide environmental interaction studies [151], variance prioritization [152], and studying EDs in specific comorbid psychopathology contexts (such as obsessionality in AN and impulsivity in $\mathrm{BN}$ ) [72, 150].

Perfectionism and obsessionality are factors in the disordered eating behavior and maintenance of low weight in $\mathrm{AN}$, and impulsivity could be among the reasons for the inability to regulate body weight despite the drive for thinness in BN. Finally, stepping beyond the diagnostic criteria of full-phenotype EDs, the important ED-related phenotypes (e.g., highest and lowest illness-related BMIs, anxiety, anhedonia, obsessionality, impulsivity, etc.) could be explored in a cross-disorder manner in order to maximize sample size and explore the possibility of common genetic etiology for these overlapping phenotypes across psychiatric diagnoses $[72,150]$.

\section{Conclusions}

In this review, we have provided a summary of the literature on the epidemiological and genetic origins of EDs. Using this evidence, we have developed a novel theoretical framework which provides a potential explanation for the overlap of different types of EDs. This framework provides a simplified view of the interaction of the potential genetics of EDs and the environment, specifically the pressure to be thin. We hope that this framework will stimulate research looking at the evolutionary roots of EDs and ED-predisposing genes. With recent technological advances (high-throughput genotyping and sequencing) the ability to detect genetic associations is improving. Understanding the genes underlying EDs may shed light on new and more effective methods of treating these disorders.

\section{Disclosure Statement}

None of the authors report having a conflict of interest. This research was conducted in the absence of any commercial or financial relationships that could be viewed as possible conflicts.

\section{Funding Sources}

Funding was provided by Canada Research Chair. The funder had no role in study design, data collection and analysis, decision to publish, or preparation of the manuscript.

\section{Author Contributions}

A.J.M. and D.M. were both responsible for developing the key concepts to be assessed by the review, drafting and revising the manuscript, providing approval for journal submission and ensuring the accuracy and integrity of the work. M.P. and J.C. provided a critical review of the manuscript. All authors agreed with the final content of the review. 


\section{References}

1 Hudson JI, Hiripi E, Pope H, Kessler RC: The prevalence and correlates of eating disorders in the National Comorbidity Survey replication. Biol Psychiatry 2008;61:348-358.

2 Striegel-Moore RH: Risk factors for eating disorders. Ann NY Acad Sci 2007;817:98109.

3 Mazzeo SE, Mitchell KS, Bulik CM, Reichborn- T, Kendler KS, Neale MC: Assessing the heritability of anorexia nervosa symptoms using a marginal maximal likelihood approach. Psychol Med 2009;39:463-473.

4 Slof-Op't Landt MCT, van Furth EF, Meulenbelt I, Slagboom PE, Bartels M, Boomsma DI, et al: Eating disorders: from twin studies to candidate genes and beyond. Twin Res Hum Genet 2005;8:467-482.

5 Thornton LM, Mazzeo SE, Bulik CM: The heritability of eating disorders: methods and current findings. Curr Top Behav Neurosci 2011;6:141-156.

6 Hinney A, Volckmar AL: Genetics of eating disorders. Curr Psychiatry Rep 2013;15.

7 American Psychiatric Association: Diagnostic and Statistical Manual of Mental Disorders, ed 5. Arlington, American Psychiatric Association, 2013.

8 Grilo CM: Why no cognitive body image feature such as overvaluation of shape/weight in the binge eating disorder diagnosis? Int J Eat Disord 2013;46:208-211.

9 Fornari VM, Braun DL, Sunday SR, Sandberg DE, Matthews M, Chen I, et al: Seasonal patterns in eating disorder subgroups. Compr Psychiatry 1994;35:450-456.

10 Favaro A, Ferrara S, Santonastaso P: The spectrum of eating disorders in young women: a prevalence study in a general population sample. Psychosom Med 2003;65:701-708.

11 Hoek HW, van Hoeken D: Review of the prevalence and incidence of eating disorders. Int Eat Disord 2003;34:383-396.

12 Currin L, Schmidt U, Treasure J, Jick H: Time trends in eating disorder incidence. Br J Psychiatry 2005;186:132-135.

13 Hoek HW: Incidence, prevalence and mortality of anorexia nervosa and other eating disorders. Curr Opin Psychiatry 2006;19:389394.

14 van Son GE, van Hoeken D, Bartelds AI, van Furth EF, Hoek HW: Time trends in the incidence of eating disorders: a primary care study in the Netherlands. Int J Eat Disord 2006;39:565-569.

15 Wade TD, Bergin JL, Tiggemann M, Bulik CM, Fairburn CG: Prevalence and long-term course of lifetime eating disorders in an adult Australian twin cohort. Aust N Z J Psychiatry 2006; $40: 121-128$.

16 Preti A, de Girolamo G, Vilagut G, Alonso J, de Graaf R, Bruffaerts R, et al: The epidemiology of eating disorders in six European countries: results of the ESEMeD-WMH project. J Psychiatr Res 2009;43:1125-1132.
17 Marques L, Alegria M, Becker A, Chen C, Fang A, Chosak A, et al: Comparative prevalence, correlates of impairment, and service utilization for eating disorders across U.S. ethnic groups: implications for reducing ethnic disparities in health care access for eating disorders. Int J Eat Disord 2011;44:412-420.

18 Heaner MK, Walsh BT: A history of the identification of the characteristics eating disturbances of bulimia nervosa, binge eating disorders and anorexia nervosa. Appetite 2013;65: 185-188.

19 Kessler RC, Berglund PA, Chiu WT, Deitz AC, Hudson JI, Shahly V, et al: The prevalence and correlates of binge eating disorder in the World Health Organization World Mental Health Surveys. Biol Psychiatry 2013; 73:904-914.

20 Franko DL, Keshaviah A, Eddy KT, Krishna M, Davis MC, Keel PK, et al: A longitudinal investigation of mortality in anorexia nervosa and bulimia nervosa. Am J Psychiatry 2013; 170:917-925.

21 Meczekalski B, Podfigurna-Stopa A, Katulski $\mathrm{K}$ : Long-term consequences of anorexia nervosa. Maturitas 2013;75:215-220.

22 Keski-Rahkonen A, Hoek HW, Linna MS Raevuori A, Sihvola E, Bulik CM, et al: Incidence and outcomes of bulimia nervosa: a nationwide population-based study. Psychol Med 2009;39:823-831.

23 Smink FRE, van Hoeken D, Hoek HW: Epidemiology of eating disorders: incidence, prevalence and mortality rates. Curr Psychiatry Rep 2012;14:406-414.

24 Kinzl JF, Traweger C, Trefalt E, Mangweth B, Biebl W: Binge eating disorder in females: a population-based investigation. Int J Eat Disord 1999;25:287-292.

25 Spitzer R., Devlin M, Walsh TB, Hasin DS, Wing R, Marcus M, et al: Binge eating disorder: a multisite field trial of the diagnostic criteria. Int J Eat Disord 1992;11:191-204.

26 Spitzer R, Yanovski SZ, Wadden T, Wing R, Marcus MD, Stunkard A, et al: Binge eating disorder: its further validation in a multi-site study. Int J Eat Disord 1993;13:137-154.

27 Hay P: The epidemiology of eating disorder behaviors: an Australian community-based survey. Int J Eat Disord 1998;23:371-382.

28 Alegria M, Woo M, Cao Z, Torres M, Meng $\mathrm{X}$, Striegel-Moore R: Prevalence and correlates of eating disorders in Latinos in the United States. Int J Eat Disord 2007;40:S15S21.

29 Grucza RA, Przybeck TR, Cloninger CR: Prevalence and correlates of binge eating disorder in a community sample. Compr Psychiatry $2007 ; 48: 124-131$.

30 Klump KL, Miller KB, Keel PK, McGue M, Iacono WG: Genetic and environmental influences on anorexia nervosa syndromes in a population-based twin sample. Psychol Med 2001;31:737-740.
31 Hoek H, van Harten PN, Hermans KME, Katzman MA, Matroos GE, Susser ES: The Incidence of Anorexia Nervosa on Curaçao. Am J Psychiatry 2005;162:748-752.

32 Striegel-Moore RH, Dohm FA, Kraemer HC, Taylor CB, Daniels S, Crawford PB, et al: Eating disorders in white and black women. Am J Psychiatry 2003;160:1326-1331.

33 Taylor JY, Caldwell CH, Baser RE, Matuski N, Faison N, Jackson JS: Classification and correlates of eating disorders among blacks: findings from the National Survey of American Life. J Health Care Poor Underserved 2013; 24:289-310.

34 Keel PK, Klump KL: Are eating disorders culture-bound syndromes? Implications for conceptualizing their etiology. Psychol Bull 2003; 129:747-769.

35 Nicdao EG, Hong S, Takeuchi DT: Prevalence and correlates of eating disorders among Asian Americans: results from the National Latino and Asian American Study. Int J Eat Disord 2007;40:S22-S26.

36 Smith DE, Marcus MD, Lewis CE, Fitzgibbon M, Schreiner P: Prevalence of binge eating disorder, obesity, and depression in a biracial cohort of young adults. Ann Behav Med 1998; 20:227-232.

37 Hay PJ, Mond J, Buttner P, Darby A: Eating disorder behaviors are increasing: findings from two sequential community surveys in South Australia. PLoS One 2008;3:e1541.

38 Keel PK, Heatherton TF, Dorer DJ, Joiner TE, Zalta AK: Point prevalence of bulimia nervosa in 1982, 1992, and 2002. Psychol Med 2006; 36:119-127.

39 Cassin SE, von Ranson KM: Personality and eating disorders: a decade in review. Clin Psychol Rev 2005;25:895-916.

40 Kaye W: Neurobiology of anorexia and bulimia nervosa. Physiol Behav 2008;94:121-135.

41 Jaite C, Hoffmann F, Glaeske G, Bachmann CJ: Prevalence, comorbidities and outpatient treatment of anorexia and bulimia nervosa in German children and adolescents. Eat Weight Disord 2013;18:157-165

42 Reichborn-Kjennerud T, Bulik CM, Sullivan PF, Tambs K, Harris JR: Psychiatric and medical symptoms in binge eating in the absence of compensatory behaviors. Obes Res 2004; 12:1445-1454.

43 Keski-Rahkonen A, Raevuori A, Bulik CM, Hoek HW, Sihvola E, Kaprio J, et al: Depression and drive for thinness are associated with persistent bulimia nervosa in the community. Eur Eat Disord Rev 2013;21:121-129.

44 Mazzeo S, Bulik C: Environmental and genetic risk factors for eating disorders: what the clinician needs to know. Child Adolesc Psychiatr Clin North 2009;18:1-15.

45 Klump KL, Wonderlich S, Lehoux P, Lilenfeld LRR, Bulik CM: Does environment matter? A review of nonshared environment and eating disorders. Int J Eat Disord 2002;31:118-135. 
46 Kardum I, Gra A, Hudek-Kneževi J: Evolutionary explanations of eating disorders. Psychol Top 2008; 17:247-263.

47 O'Shaughnessy R, Dallos R: Attachment research and eating disorders: a review of the literature. Clin Child Psychol Psychiatry 2009;14:559-574.

48 Holtom-Viesel A, Allan S: A systematic review of the literature on family functioning across all eating disorder diagnoses in comparison to control families. Clin Psychol Rev 2014;34:29-43.

49 Fairburn CG, Harrison PJ: Eating disorders. Lancet 2003;361:407-416.

50 Kaye WH, Wierenga CE, Bailer UF, Simmons AN, Bischoff-Grethe A: Nothing tastes as good as skinny feels: the neurobiology of anorexia nervosa. Trends Neurosci 2013;36: 110-120.

51 Wierenga CE, Ely A, Bischoff-Grethe A, Bailer UF, Simmons AN, Kaye WH: Are extremes of consumption in eating disorders related to an altered balance between reward and inhibition? Front Behav Neurosci 2014;8:410.

52 Jacobi C, Hayward C, de Zwaan M, Kraemer HC, Agras WS: Coming to terms with risk factors for eating disorders: application of risk terminology and suggestions for a general taxonomy. Psychol Bull 2004;130:19-65.

53 Kaye WH, Wierenga CE, Bailer UF, Simmons AN, Bischoff-Grethe A: Nothing tastes as good as skinny feels: the neurobiology of anorexia nervosa. Trends Neurosci 2013;36: $110-120$.

54 O’Hara CB, Campbell IC, Schmidt U: A reward-centred model of anorexia nervosa: a focussed narrative review of the neurological and psychophysiological literature. Neurosci Biobehav Rev 2015;52:131-152.

55 O'Hara CB, Keyes A, Renwick B, Leyton M, Campbell IC, Schmidt U: The effects of acute dopamine precursor depletion on the reinforcing value of exercise in anorexia nervosa. PLoS One 2016;11:e0145894.

56 Teare MD, Barrett J: Genetic epidemiology 2: genetic linkage studies. Lancet 2005;366: 1036-1044

57 Zhu M, Zhao S: Candidate gene identification approach: progress and challenges. Int J Biol Sci 2007;3:420-427.

58 Bush WS, Moore JH: Chapter 11: Genomewide association studies. PLoS Comput Biol 2012;8:e1002822.

59 Booij L, Casey KF, Antunes JM, Szyf M, Joober R, Israël $M$, et al: DNA methylation in individuals with anorexia nervosa and in matched normal-eater controls: a genomewide study. Int J Eat Disord 2015;48:874-882.

60 Wray NR, Visscher PM: Estimating trait heritability. Nat Educ 2008;1:29.

61 Tenesa A, Haley CS: The heritability of human disease: estimation, uses and abuses. Nat Rev 2013;14:139-149.
62 Munn-Chernoff M, Grant JD, Agrawal A, Koren R, Glowinski AL, Bucholz KK, et al: Are there common familial influences for major depressive disorder and an overeating-binge eating dimension in both European-American and African-American female twins? Int J Eat Disord 2015;48:375-382.

63 Munn-Chernoff M, Grant JD, Agrawal A, Sartor CE, Werner KB, Bucholz KK, et al: Genetic overlap between alcohol use disorder and bulimic behaviors in European American and African American women. Drug Alcohol Depend 2016;153:335-340.

64 Lander E, Kruglyak L: Genetic dissection of complex traits: guidelines for interpreting and reporting linkage results. Nat Genet 1995; 11:241-247.

65 Grice DE, Halmi KA, Fichter MM, Strober M, Woodside DB, Treasure JT, et al: Evidence for a susceptibility gene for anorexia nervosa on chromosome 1. Am J Hum Genet 2002;70: 787-792.

66 Devlin B, Bacanu S-A, Klump KL, Bulik CM, Fichter MM, Halmi KA, et al: Linkage analysis of anorexia nervosa incorporating behavioral covariates. Hum Mol Genet 2002;11:689-696.

67 Bulik CM, Devlin B, Bacanu S-A, Thornton L, Klump KL, Fichter MM, et al: Significant linkage on chromosome 10p in families with bulimia nervosa. Am J Hum Genet 2003;72:200207.

68 Hager J, Dina C, Francke S, Dubois S, Houari $M$, Vatin V, et al: A genome-wide scan for human obesity genes reveals a major susceptibility locus on chromosome 10. Nat Genet 1998; 20:304-308

69 Hinney A, Ziegler A, Oeffner F, Wedewardt C, Vogel M, Qulftange H, et al: Independent confirmation of a major locus for obesity on chromosome 10. J Clin Endocrinol Metab 2000;85:2962-2965.

70 Groves CJ, Zeggini E, Walker M, Hitman GA, Levy JC, O'Rahilly S, et al: Significant linkage of BMI to chromosome 10p in the U.K. population and evaluation of GAD2 as a positional candidate. Diabetes 2006;55:1884-1889.

71 Li A, Meyre D: Challenges in reproducibility of genetic association studies: lessons learned from the obesity field. Int J Obes 2013;559567.

72 Yilmaz Z, Hardaway JA, Bulik CM: Genetics and epigenetics of eating disorders. Adv Genomics Genet 2015;5:131.

73 Monteleone P, Maj M: Dysfunctions of leptin, ghrelin, BDNF and endocannabinoids in eating disorders: beyond the homeostatic control of food intake. Psychoneuroendocrinology 2013;38:312-330.

74 Trace SE, Baker JH, Peñas-Lledó E, Bulik CM: The genetics of eating disorders. Annu Rev Clin Psychol 2013;9:589-620.

75 Brandys MK, Van Elburg AA, Loos RJF, Bauer F, Hendriks J, Van Der Schouw YT, et al: Are recently identified genetic variants regulating BMI in the general population associated with anorexia nervosa? Am J Med Genet B Neuropsychiatr Genet 2010;153:695-699.
76 Gervasini G, Gamero-Villarroel C: Discussing the putative role of obesity-associated genes in the etiopathogenesis of eating disorders. Pharmacogenomics 2015;16:12871305.

77 Hinney A, Kesselmeier M, Jall S, Volckmar A-L, Föcker M, Antel J, et al: Evidence for three genetic loci involved in both anorexia nervosa risk and variation of body mass index. Mol Psychiatry 2017;22:192-201.

78 Bulik-Sullivan B, Finucane HK, Anttila V, Gusev A, Day FR, et al: An atlas of genetic correlations across human diseases and traits. Nat Genet 2015;47:1236-1241.

79 Wang K, Zhang H, Bloss CS, Duvvuri V, Kaye W, Schork NJ, et al: A genome-wide association study on common SNPs and rare CNVs in anorexia nervosa. Mol Psychiatry 2011;16: 949-959.

80 Winham SJ, Cuellar-Barboza AB, McElroy SL, Oliveros A, Crow S, Solby CL, et al: Bipolar disorder with comorbid binge eating history: a genome-wide association study implicates APOB. J Affect Disord 2014;165:151158.

81 Boraska V, Davis OSP, Cherkas LF, Helder SG, Harris J, Krug I, et al: Genome-wide association analysis of eating disorder-related symptoms, behaviors, and personality traits. Am J Med Genet B Neuropsychiatr Genet 2012;159B:803-811.

82 Boraska V, Franklin CS, Floyd JAB, Thornton LM, Huckins LM, Southam L, et al: A genome-wide association study of anorexia nervosa. Mol Psychiatry 2014;19:1085-1094.

83 Li D, Chang X, Connolly JJ, Tian L, Liu Y, Bhoj EJ, et al: A genome-wide association study of anorexia nervosa suggests a risk locus implicated in dysregulated leptin signaling. Sci Rep 2017;7:3847.

84 Duncan L, Yilmaz Z, Gaspar H, Walters R, Goldstein J, Anttila V, et al: Significant locus and metabolic genetic correlations revealed in genome-wide association study of anorexia nervosa. Am J Psychiatry 2017;174:850-858.

85 Wade TD, Gordon S, Medland S, Bulik CM, Heath AC, Montgomery GW, et al: Genetic variants associated with disordered eating. Int J Eat Disord 2013;46:594-608.

86 Cui H, Moore J, Ashimi SS, Mason BL, Drawbridge JN, Han S, et al: Eating disorder predisposition is associated with ESRRA and HDAC4 mutations. J Clin Invest 2013;123: 4706-4713.

87 Darcy MJ, Calvin K, Cavnar K, Ouimet CC Regional and subcellular distribution of HDAC4 in mouse brain. J Comp Neurol 2010; 518:722-740.

88 Sando III R, Gounko N, Pieraut S, Liao L, Yates III J, Maximov A: HDAC4 governs a transcriptional program essential for snypatic plasticity and memory. Cell 2010;151:821834

Mayhew/Pigeyre/Couturier/Meyre 
89 Mattson MP: Mitochondrial regulation of neuronal plasticity. Neurochem Res 2007; 32:707-715.

90 Ren Y, Jiang H, Ma D, Nakaso K, Feng J: Parkin degrades estrogen-related receptors to limit the expression of monoamine oxidases. Hum Mol Genet 2011;20:1074-1083.

91 Liu D, Zhang Z, Gladwell W, Teng CT: Estrogen stimulates estrogen-related receptor a gene expression through conserved hormone response elements. Endocrinology 2003;144:4894-4904.

92 Bochukova EG, Huang N, Keogh J, Henning E, Purmann C, Blaszczyk K, et al: Large, rare chromosomal deletions associated with severe early-onset obesity. Nature 2010;463: 666-670.

93 Walters RG, Jacquemont S, Valsesia A, de Smith A, Martinet D, Andersson J, et al: A new highly penetrant form of obesity due to deletions on chromosome 16p11.2. Nature 2010;463:671-675.

94 Doche ME, Bochukova EG, Su H, Pearce LR, Keogh JM, Henning E, et al: Human SH2B1 mutations are associated with maladaptive behaviors and obesity. J Clin Invest 2012; 122:4732-4736

95 Gill R, Chen Q, D’Angelo D, Chung WK: Eating in the absence of hunger but not loss of control behaviors are associated with 16p11.2 deletions. Obesity 2014;22:26252631.

96 Maillard AM, Hippolyte L, Rodriguez-Herreros B, Chawner SJRA, Dremmel D, Agüera $\mathrm{Z}$, et al: 16P11.2 Locus modulates response to satiety before the onset of obesity. Int J Obes (Lond) 2015;40:870-876.

97 Jacquemont S, Reymond A, Zufferey F, Harewood L, Walters RG, Kutalik Z, et al: Mirror extreme BMI phenotypes associated with gene dosage at the chromosome 16p11.2 locus. Nature 2011;478:97-102.

98 Strober M, Peris T, Steiger H: The plasticity of development: how knowledge of epigenetics may advance understanding of eating disorders. Int J Eat Disord 2014;47:696704.

99 Frieling H, Gozner A, Römer KD, Lenz B, Bönsch D, Wilhelm J, et al: Global DNA hypomethylation and DNA hypermethylation of the alpha synuclein promoter in females with anorexia nervosa. Mol Psychiatry 2007; 12:229-230.

100 Frieling H, Bleich S, Otten J, Römer KD, Kornhuber J, de Zwaan M, et al: Epigenetic downregulation of atrial natriuretic peptide but not vasopressin mRNA expression in females with eating disorders is related to impulsivity. Neuropsychopharmacology 2008; 33:2605-2609.

101 Kim Y-R, Kim J-H, Kim MJ, Treasure J: Differential methylation of the oxytocin receptor gene in patients with anorexia nervosa: a pilot study. PLoS One 2014;9:e88673.
102 Ehrlich S, Weiss D, Burghardt R, InfanteDuarte C, Brockhaus S, Muschler MA, et al: Promoter specific DNA methylation and gene expression of POMC in acutely underweight and recovered patients with anorexia nervosa. J Psychiatr Res 2010;44:827-833.

103 Frieling H, Rómer KD, Scholz S, Mittelbach F, Wilhelm J, De Zwaan M, et al: Epigenetic dysregulation of dopaminergic genes in eating disorders. Int J Eat Disord 2010;43:577583.

104 Saffrey R, Novakovic B, Wade TD: Assessing global and gene specific DNA methylation in anorexia nervosa: a pilot study. Int J Eat Disord 2014;47:206-210.

105 Tremolizzo L, Conti E, Bomba M, Uccellini O, Rossi MS, Marfone M, et al: Decreased whole-blood global DNA methylation is related to serum hormones in anorexia nervosa adolescents. World J Biol Psychiatry 2014; 15:327-333.

106 Kesselmeier M, Pütter C, Volckmar A-L, Baurecht $\mathrm{H}$, Grallert H, Illig T, et al: Highthroughput DNA methylation analysis in anorexia nervosa confirms TNXB hypermethylation. World J Biol Psychiatry, Epub ahead of print.

107 Perroud N, Paoloni-Giacobino A, Prada P, Olié E, Salzmann A, Nicastro R, et al: Increased methylation of glucocorticoid receptor gene $(\mathrm{NR} 3 \mathrm{C} 1)$ in adults with a history of childhood maltreatment: a link with the severity and type of trauma. Transl Psychiatry 2011;1:e59.

108 Baker JH, Maes HH, Lissner L, Aggen SH, Lichtenstein P, Kendler KS: Genetic risk factors for disordered eating in adolescent males and females. J Abnorm Psychol 2002; 118:576-586.

109 Keski-Rahkonen A, Bulik CM, Neale BM Rose RJ, Rissanen A, Kaprio J: Body dissatisfaction and drive for thinness in young adult twins. Int J Eat Disord 2005;37:188199.

110 Keski-Rahkonen A, Neale BM, Bulik CM, Pietilainen KH, Rose RJ, Kaprio J, et al: Intentional weight loss in young adults: sexspecific genetic and environmental effects. Obes Res 2005;13:745-753.

111 Slof-Op 't Landt MCT, Bartels M, Van Furth EF, Van Beijsterveldt CEM, Meulenbelt I, Slagboom PE, et al: Genetic influences on disordered eating behaviour are largely independent of body mass index. Acta Psychiatr Scand 2008;117:348-356.

112 Wolfe BE, Baker CW, Smith AT, KellyWeeder S: Validity and utility of the current definition of binge eating. Int J Eat Disord 2009;42:674-686.

113 Reichborn-Kjennerud T, Bulik CM, Kendler KS, Røysamb E, Maes H, Tambs K, et al: Gender differences in binge-eating: a population-based twin study. Acta Psychiatr Scand 2003;108:196-202.
114 Neul JL, Kaufmann WE, Glaze DG, Clarke AJ, Leonard H, Bailey MES, et al: Rett syndrome: revised diagnostic criteria and nomenclature. Ann Neurol 2010;68:944-950.

115 Klump KL, Burt A, McGue M, Iacono W: Changes in genetic and environmental influences on disordered eating between early and late adolescence: a longitudinal twin study. Psychol Med 2007;45:3249-3258

116 Silberg JL, Bulik CM: The developmental association between eating disorders symptoms and symptoms of depression and anxiety in juvenile twin girls. J Child Psychol Psychiatry 2005;46:1317-1326.

117 Culbert KM, Burt A, McGue M, Iacono WG, Klump KL: Puberty and the genetic diathesis of disordered eating attitudes and behaviors. J Abnorm Psychol 2009;118:788-796.

118 Östlund H, Keller E, Hurd YL: Estrogen receptor gene expression in relation to neuropsychiatric disorders. Ann NY Acad Sci 2003; 1007:54-63.

119 Asarian L, Geary N: Sex differences in the physiology of eating. Am J Physiol Regul Integr Comp Physiol 2013;305:R1215-R1267.

120 Wasser SK, Barash DP: Reproductive suppression among female mammals: implications for biomedicine and sexual selection theory. Q Rev Biol 1983;58:513-538.

121 Abed R: The sexual competition hypothesis for eating disorders. Br J Med Psychol 1998; 71:525-547.

122 Guisinger S: Adapted to flee famine: adding an evolutionary perspective on anorexia nervosa. Psychol Rev 2003;110:745-761.

123 Wells JCK: The evolution of human fatness and susceptibility to obesity: an ethological approach. Biol Rev 2006;81:183-205.

124 Speakman JR, Levitsky DA, Allison DB, Bray MS, de Castro JM, Clegg DJ, et al: Set points, settling points and some alternative models: theoretical options to understand how genes and environments combine to regulate body adiposity. Dis Model Mech 2011;4:733-745.

125 Field AE, Sonneville KR, Micali N, Crosby $\mathrm{RD}$, Swanson SA, Laird NM, et al: Prospective association of common eating disorders and adverse outcomes. Pediatrics 2012;130: e289-e295.

126 Kaye WH, Klump KL, Frank GK, Strober M Anorexia and bulimia nervosa. Annu Rev Med 2000;51:299-313.

127 Neel J V: Diabetes mellitus: a "thrifty" genotype rendered detrimental by "progress." Am J Hum Genet 1962;14:353-362.

128 Swinburn BA, Sacks G, Hall KD, McPherson K, Finegood DT, Moodie ML, et al: The global obesity pandemic: shaped by global drivers and local environments. Lancet 2011;378:804-814.

129 Mitchell NS, Catenacci VA, Wyatt HR, Hill JO: Obesity: overview of an epidemic. Psychiatr Clin North Am 2011;34:717-732.

130 Scolnick B, Mostofsky DI: Anorexia nervosa: a rogue hibernation? Med Hypotheses 2014;82:231-235. 
131 Farooqi SI, Keogh JM, Yeo GSH, Lank EJ, Cheetham T, O'Rahilly S: Clinical spectrum of obesity and mutations in the melanocortin 4 receptor gene. N Engl J Med 2003;348: 2373-2383.

132 Geller F, Reichwald K, Dempfle A, Illig T, Vollmert C, Herpertz S, et al: Melanocortin-4 receptor gene variant I103 is negatively associated with obesity. Am J Hum Genet 2004;74:572-581.

133 Stutzmann F, Vatin V, Cauchi S, Morandi A, Jouret B, Landt $\mathrm{O}$, et al: Non-synonymous polymorphisms in melanocortin-4 receptor protect against obesity: the two facets of a Janus obesity gene. Hum Mol Genet 2007; $16: 1837-1844$

134 Hebebrand J, Fichter M, Gerber G, Goerg T, Hermann H, Geller F, et al: Genetic predisposition to obesity in bulimia nervosa: a mutation screen of the melanocortin- 4 receptor gene. Mol Psychiatry 2002;7:647-651.

135 Branson R, Potoczna N, Kral JG, Lentes KU, Hoehe MR, Horber FF: Binge eating as a major phenotype of melanocortin 4 receptor gene mutations. N Engl J Med 2003;348: 1096-1103.

136 Stutzmann F, Tan K, Vatin V, Dina C, Jouret $B$, Tichet J, et al: Prevalence of melanocortin-4 receptor deficiency in Europeans and their age-dependent penetrance in multigenerational pedigrees. Diabetes 2008;57: 2511-2518.
137 Gamero-Villarroel C, Rodriguez-Lopez R, Jimenez M, Carrillo JA, Garcia-Herraiz A, Albuquerque D, et al: Melanocortin-4 receptor gene variants are not associated with binge-eating behavior in nonobese patients with eating disorders. Psychiatr Genet 2015 25:35-38.

138 Urwin RE, Bennetts BH, Wilcken B, Beumont PJ V, Russell JD, Nunn KP: Investigation of epistasis between the serotonin transporter and norepinephrine transporter genes in anorexia nervosa. Neuropsychopharmacology 2003;28:1351-1355.

139 Urwin RE, Nunn KP: Epistatic interaction between the monoamine oxidase $\mathrm{A}$ and serotonin transporter genes in anorexia nervosa. Eur J Hum Genet 2005;13:370-375.

140 Thaler L, Groleau P, Badawi G, Sycz L, Zeramdini N, Too A, et al: Epistatic interactions implicating dopaminergic genes in bulimia nervosa $(\mathrm{BN})$ : relationships to eating- and personality-related psychopathology. Prog Neuropsychopharmacol Biol Psychiatry 2012;39:120-128.

141 Stice E, Shaw HE: Role of body dissatisfaction in the onset and maintenance of eating pathology: a synthesis of research findings. J Psychosom Res 2002;53:985-993.

142 Neumark-Sztainer DR, Wall MM, Haines JI, Story MT, Sherwood NE, van den Berg PA: Shared risk and protective factors for overweight and disordered eating in adolescents. Am J Prev Med 2007;33:359-369.

143 Pike KM, Dohm FA, Striegel-Moore RH, Wilfley DE, Fairburn CG: A comparison of black and white women with binge eating disorder. Am J Psychiatry 2001;158:14551460 .
144 Gluck ME, Geliebter A: Racial/ethnic differences in body image and eating behaviors. Eat Behav 2002;3:143-151.

145 Simpson KJ: Anorexia nervosa and culture. J Psychiatr Ment Health Nurs 2002;9:65-71.

146 Becker AE, Fay K, Gilman SE, StriegelMoore R: Facets of acculturation and their diverse relations to body shape concern in Fiji. Int J Eat Disord 2007;40:42-50.

147 Becker AE, Burwell RA, Gilman SE, Herzog DB, Hamburg P: Eating behaviours and attitudes following prolonged exposure to television among ethnic Fijian adolescent girls. Br J Psychiatry 2002;180:509-514.

148 Klump KL: Puberty as a critical risk period for eating disorders: a review of human and animal studies. Horm Behav 2013;64:399_ 410.

149 Stephens M, Baliding DJ: Bayesian statistical methods for genetic association studies. Nat Rev Genet 2009;10:681-90.

150 Bulik CM, Kleiman SC, Yilmaz Z: Genetic epidemiology of eating disorders. Curr Opin Psychiatry 2016;383-388.

151 Aschard H, Lutz S, Maus B, Duell EJ, Fingerlin TE, Chatterjee N, et al: Challenges and opportunities in genome-wide environmental interaction (GWEI) studies. Hum Genet 2012;131:1591-1613.

152 Deng WQ, Paré G: A fast algorithm to optimize SNP prioritization for gene-gene and gene-environment interactions. Genet Epidemiol 2011;35:729-738. 